\title{
MEDÉIA - 0 SILÊNCIO ÉTICO DE ARISTÓTELES
}

\author{
MARIA CECÍLIA DE MIRANDA N. COELHO \\ Fundação Brasileira de Teatro
}

\begin{abstract}
RESUMO: O presente ensaio faz uma análise de peça/personagem Medéia,de Eurlpides, a partir da boptica/śtica aristotélica. Se não fosse uma herolna trágica poderia ser Medêia, pelo menos, uma "pessoa ética"? Na Ética a Nicómaco, Eurlpides é um dos pensadores mais citados por Aristóteles mas, por que o filósofo silencia sobre as açōes de Medéia?
\end{abstract}

Palavras-chave: Aristóteles, Ética, Poética; Euripides, Medeía

É diffcil, ao ouvirmos os nomes de Medéia e Aristóteles, não sermos levados a pensar no excesso (paixão) contra a mediania (razão). Esta é uma oposição clássica que, mesmo nos textos mais críticos, ainda é mantida. Veja-se, por exemplo, o capítulo I da obra de S. P. Rouanet, $A$ razão cativa (Rouanet, 1987, p. 16).

Mas, até que ponto paixão e razão se distanciam tanto?

Tomando como base a Ética a Nicómaco - texto dos mais significativos, não só de Aristóteles, mas de toda a tradição filosófica ocidental, principalmente no que diz respeito à defesa da virtude como mediania - pretendo fazer uma análise da personagem Medéia.

Ressalto que, neste trabalho, não tenho como objetivo julgar a Ética proposta por Aristóteles, tampouco as ações executadas por Medéia, mas sim, do ponto de vista analítico, propor uma relação entre ambas, ou seja, se aceitarmos o que é dito na Ética, então não poderemos condenar as açōes de Medéia.

Um dos elementos que me sugeriram esta relação foi o próprio silêncio de Aristóteles, no que se refere à Medéia, quando, em sua obra, Eurípides é um dos nomes mais citados $(1110 \mathrm{a} 25,1136 \mathrm{a} 10,1142 \mathrm{a} 5,1155 \mathrm{~b} 25,1155 \mathrm{~b} 5,1167 \mathrm{a} 30,1168 \mathrm{~b} 5)$ e o crime de Alcmêon - o reverso do infanticídio de Medéia - é analisado, pelo menos, em duas passagens (1110a25, 1136a10). Por que 0 silêncio? E bom lembrar que as referências feitas à Medéia, na Poética (1453b26, 1454a33), são, como seria de se esperar, de caráter mais técnico. Mas, se achei sugestivo tal silêncio, não pretendo apoiar-me neste "não falar" e sim no "falar" de Aristóteles.

Ao tratar da eticidade das açōes de Medéia, não posso deixar de tratar, paralelamente, do próprio problema da ação em si mesma - afinal, defende-se que a tragédia Medéia não tem uma heroína trágica, mas, apenas, uma figura trágica passional (Kitto, 1954, pp. 200-2).

Portanto, consideremos as seguintes afirmaçōes de Aristóteles:

"A tragédia é a imitação de uma ação de caráter elevado (...) e que a piedade tem por efeito a purificação dessa emoçōes. (...) se executa mediante personagens que agem e que diversamente se apresentam conforme o caráter e o pensamento." (Poética, 1149b24-28, 35-40)

"Ora, se a função do homem é uma atividade da alma que segue ou implica um princípio 
racional (...) se realmente assim é (e afirmamos ser a função do homem uma certa espécie de vida, e esta vida uma atividade ou ações da alma que implicam um princípio racional; e acrescentamos que a função do homem é uma boa e nobre realização das mesmas; e que qualquer ação é bem realizada quando está de acordo com a excelência que The é própria; se realmente assim é) o bem do homem nos aparece como uma atividade da alma em consonância com a virtude, e, se há mais uma, com a melhor e a mais completa." (Ét. Nic., 1098a5-20).

Qual a ação de Medéia? Quando se inicia a peça, ela jấ traiu o pai e a pátria pelo amor de Jasão, já matou o irmão, e, instigada pelo amado, levou as filhas de Pélias a matarem o pai. Ela também já foi traída pelo marido, assim sendo, apenas sofre, como nos mostram as falas da ama e a sua:

(Ama)"... e jaz sem alimento, abandonando o corpo ao sofrimento, consumindo só em pranto seus dias todos desde que sofreu a injúria do esposo." (vv.31-34)

(Medéia) “... como sou infeliz! Que sofrimento o meu, desventurada! Ai de mim! Por que não morro?" ( $v$.115-116)

Além disto, tanto a ama quanto Medéia já reconheceram o erro desta: aqueles que ela pensava serem seus inimigos (pai, irmão e pátria) são (re)conhecidos como amigos:

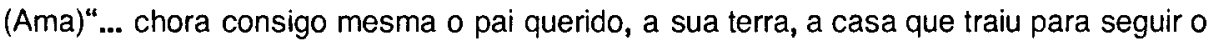
homem que hoje a despreza.

(...) sente a coitada quão melhor teria sido se não abandonasse a terra de seus pais." (vv. 39-44)

(Medéia) "Meu pai, minha cidade de onde vim para viver tão longe, após haver iniquamente morto meu irmão." (vv. 182-184)

Tendo em vista os elementos antes citados, serlamos levados a dizer que não há ação em Medéia, pois nāo existem "personagens que agem", mas apenas que sofrem e tal sofrimento, de fato, estender-se-á ao longo de toda a peça.

Mas, não poderíamos ver Medéia como "personagem que age" e "que se apresenta conforme o caráter e o pensamento", à medida que ela não aceita apenas sofrer em vão, como "miserável muther", condição à qual se sujeitavam normalmente as mulheres, conforme relato do monólogo em que ela se dirige às mulheres de Corinto, e que entende ser até válida, quando houver nisso uma finalidade maior?

(Medéia) "Mas uma só linguagem não é adequada a vós e a mim. Aqui tendes cidadania, o lar paterno e mais doçuras desta vida, a convivência com os amigos. Estou só, proscrita, vítima dos ultrajes de um marido (...). O mais das vezes a mulher é temerosa, covarde para a luta e fraca para as armas; se, todavia, vê lesados os direitos do leito conjugal, ela se torna, entāo, de todas as criaturas a mais sanguinária." ( $v$ v. 284-288; 298-302)

Vemos, aqui, que a reclamação de Medéia consiste no fato de não ser ela atendida como uma mulher grega. Isto se torna mais nitido se nos lembrarmos de que ela consideraria perdoável $o$ ato de Jasão, caso ele não tivesse ainda uma descendência. (vv. 554-556)

É comum, no entanto, naturalizar (animalizar) a ação/paixão de Medéia e falar de seus sentimentos primitivos, do seu ódio sobre-humano; a ama fala de seu olhar feroz (tauroyménen - v. 92), humor selvagem (ágrion éthos - v. 103), indomável coração (megalósplagkhnos dyskatápaustos - v. 109) e tanto ela quanto Jasão chegam a compará-la a uma leoa (vv. 209; 1533). 

siçãe;

Entretanto, acompanhando Aristóteles, estarlamos inclinados a adotar uma outra po-

"As paixōes irracionais não são consideradas menos humanas do que a razão; também as ações que procedem da cólera ou do apetite são ações do homem." (Ét. Nic., 1111b5)

Assim sendo, Medéia age revelando um "caráter elevado", ao preferir perder os filhos (que poderiam ter fugido com ela, se atendesse unicamente ao seu "instinto maternal") a priválos de uma vida ou morte honradas.

(Medéia ao coro) "Mas aqui mudo o meu modo de falar, pois tremo só de pensar em algo que também farei: Inda devo matar meus filhos e ninguém poderá livrá-los desse fim." (vv. 903-906)

Se, como afirma Aristóteles, a função do homem é uma certa espécie de vida que segue um princípio racional, quando Medéia revela seu pensamento e comete os assassinatos, estas açōes têm, pelo menos, três significados e/ou finalidades:

$1^{\circ)}$ Ato nobre, por não deixar que seus filhos ficassem sujeitos a uma vida indigna (desterrados ou numa familia que não fosse a deles) ou a uma morte indigna (pelas mãos dos corintios). Em relação à primeira hipótese, embora o habitual no mundo grego fosse que, após uma separação, os filhos não acompanhassem a mãe, "pois constitulam propriedade paterna" (Fonseca, 1987, p. 109), como poderia Medéia deixar seus filhos com o "homem mais vil de todos"?

$\left.2^{\circ}\right)$ Ato nobre porque, com o sacrifficio dos filhos, Jasão será punido por ter errado ao quebrar um juramento feito. E sua punição será maior ainda pela perda da(s) esposa(s)/nova descendência e do sogro/pátria.

A morte de Jasão, juntamente com a de Creúsa e Creonte (hipótese levantada por Medéia), seria, porventura, um castigo pelo erro cometido? Na visão aristotélica, o que define um homem é ser animal político. Se Medéia fosse seguir só o coração/paixão, talvez matasse Jasão. Mas ela parece agir seguindo um principio racional, que encontra apoio na seguinte afirmação de Aristóteles:

"Ora, por auto-suficiente não entendemos aquilo que é suficiente para um homem só, para aquele que leva uma vida solitária, mas também para os pais, os fithos, a esposa, e, em geral, para os amigos e concidadãos, visto que o homem nasceu para a cidadania." (Ét. Nic., 1097b5-10)

Assim, para que Jasão seja punido é necessário que seus alicerces sejam destruídos; desta forma , a morte de Creonte e de Creúsa não é uma perversidade desnecessária, como afirma Kitto (Kitto, 1954, p. 200), por exemplo. Notemos, aqui, quão complicadas são as conseqüências de urna ética/teoria filosófica!

$\left.3^{9}\right)$ Ato nobre porque Medéia não segue apenas seu "instinto" (como leoa) para viver com os filhos, isoladamente; este é o sacrificio que the cabe fazer por ter errado.

(Medéia)"Vai minha mão desgraçada! Empunha a espada! Empunha-a! Marcha para a porta que te encaminha a uma existência miserável e não fraquejes! Não lembres de todo o bem que thes queres e de que os puseste no mundo! Esquece por uns momentos que eles são teus - e depois chora, pois tens tanto amor por eles e vai matá-los! ( $\mathrm{vv}$. 1420-1427)

Talvez o erro primeiro de Medéia tenha sido o de acreditar no homem/sociedade grega. Jasāo se vangloria (vv. 613-20) de ter dado a ela a oportunidade de viver dentro das leis e co- 
nhecer a justiça no solo grego. Mas ela não estaria justamente reclamando desta justiça, ao falar do absurdo do poder da palavra para ocultar o mal (vv. 665-672)? E, embora haja a afirmação de que Medéia não é uma heroina trágica, por ser muito simples e extrema (Kitto, 1954, p. 202), nós não poderlamos vê-la como personagem complexa, quando ela mesma, ao falar do modo ardiloso como dialogou com Creonte e Jasão (vv. 415-420; 938-944), se vé presa a "cadeias que lhe parecem artificiais"? Reporto-me, aqui, por comparação, à expressão utilizada por Jaeger ao descrever a situação dos cidadãos contemporâneos de Eurípides. Segundo este helenista, os diálogos da peça Medéia mostram a necessidade que a sociedade tinha, naquele momento, de justificar-se a si própria. (Jaeger, 1987, pp. 276-7).

Desta forma, o terror e a piedade que a tragédia deve despertar podem ser encontrados, o primeiro, quando Medéia diz que, se os filhos devem ser mortos, isto deverá ser feito por ela, que lhes deu a vida; o segundo, no fato de ela ser "infeliz sem o merecer", visto ter caido no infortúnio não porque fosse vil ou malvada, mas por força de um erro, que talvez tenha sido o de pertencer à pólis grega. Esta visão menos moralista da ação de Medéia sustenta-se tanto em análises mais recentes, como as de Else e Vernant, quanto na visão, mais antiga, de Aristóteles. Portanto, terminemos este trabalho com os comentários dos referidos autores:

"(...) sem dúvida a principal razão é a miopia com a qual a seqüência do argumento de Aristóteles tem sido considerada, assim hamartía foi pensada como uma parte do caráter do herói ou pelo menos de sua experiência pessoal, enquanto reconhecimento era puramente um dispositivo técnico, uma parte do mito. Nossas descobertas mostram que hamartia também é uma parte do mito." (Else, 1957, p. 385)

"O drama antigo explora os mecanismos pelos quais um individuo, por melhor que seja, é conduzido à perdição, não pelo domínio da coação, nem pelo efeito de sua pervesidade ou de seus vícios, mas em razāo de uma falta, de um erro, que qualquer um pode cometer. Dese modo ele desnuda o jogo de forças contraditórias a que o homem está submetido, pois toda sociedade, toda cultura, da mesma forma que a grega implica tensōes e conflitos." (Vernant, 1991, p. 96)

"(...) os que afirmam ser objeto de desejo o bem aparente devem admitir que não existe objeto natural de desejo mas apenas o que parece bom a cada homem é desejado por ele." (Aristóteles, Ét. Nic. 1113a20)

\section{ABSTRACT}

The present essay makes an analysis of the play/personage Medea, of Euripides, based on Aiistotle's optic/ethics. If not a tragic heroine could Medea be, at least, an ethical person? Euripides is one of the authors most quoted by Aristotle. But why does the philosopher keep silence about Medea's actions?

\section{REFERËNCIAS BIBLIOGRÁFICA}

ARISTOTELES. Poética. Traduçăo de Eudoro de Sousa. São Paulo: Abril Cultural, 1973.

—_. Etica a Nicómaco. Tradução de Leonel Vallandro, Gerd Bornhein. São Paulo: Abril Cultural, 1973.

. Ethica Nicomachea. Oxford: Oxford University Press, 1959.

ELSE, G. Aristotles Poetics: The Argument. Cambridge: Cambridge University Press, 1957. 
EURIPIDES. Medéia. Tradução de Mario da G. Kury. Rio de Janeiro: Civilizaçāo Brasileira, 1977.

- Medéia. London: W. Heinemann, 1946.

FONSECA, I. B. B. "O divórcio no direito ático". In: PINTO, N. F., BRANDAO, J. L. (org.), Cultura Clássica em Debate, Belo Horizonte: p. 103-111,1987.

JAEGER, W. Paidéia. Tradução de Artur M. Parreira. São Paulo: Martins Fontes, 1987.

KITTO, H. D. F. Greek Tragedy. London, Methuen, 1954.

ROUANET, S. P. A Razão Cativa. São Paulo: Brasiliense, $2^{2}$ ed., 1987.

THEML, N. Medéia - espaço/tempo-mítico/histórico. In: BRANDĀO, J. L. (org.), O Enigma em Edipo Rei. Belo Horizonte: p. 254-260, 1985.

VERNANT, J. P. "O Sujeito Trágico: historicidade e trans-historicidade". In: VERNANT, J. P., VIDAL-NAQUET, P. Mito e Tragédia na Grécia Antiga. Tradução de Bertha H. Gurovitz. Sảo Paulo: Brasiliense, vol. 2, 1991. 